\title{
Technocenological approach to development of power generation of industrial regions
}

\author{
Ivan Paskar $^{1 *}$, Fedor Nepsha ${ }^{1}$, and Gennadij Lebedev ${ }^{1}$ \\ ${ }^{1}$ T.F. Gorbachev Kuzbass State Technical University, 28 street Vesennyaya, Kemerovo, 650000, \\ Russian Federation
}

\begin{abstract}
The prerequisites for the implementation of distributed generation facilities in the power grid complex of the region are highlighted. A technocenological approach has been chosen for the economically and technically sound implementation of power sources. The procedures for the verification and visualization of the technocenosis were carried out, and the stability of the existing generation system was determined. The analysis of the generating complex with the power units expected to be commissioned has been carried out. It is concluded that it is necessary to install a distributed generation facility of low power to improve energy security.
\end{abstract}

\section{Introduction}

Reliable power supply is an important aspect of the quality development of the mining industry. In connection with the active implementation of digitalization in technological and economic processes, the issue of power quality is also important.

Serious accidents that occurred in the Kuzbass power system indicate that large-scale power generation cannot always provide the required level of reliability of power supply and safety of enterprises. For example, as a result of a large-scale accident that occurred on January 26, 2014 on a double-circuit overhead line of the $110 \mathrm{kV}$ overhead line Belovskaya - Novoleninskaya-1, 2, 7 coal enterprises were stopped and more than 1000 people were evacuated on the surface [7]. On April 4, 2015, a fire broke out at one of the autotransformers of the $220 \mathrm{kV}$ substation, which led to the de-energization of $9110 \mathrm{kV}$ substations, $735 \mathrm{kV}$ substations, 2 coal mines, and in the power district, power consumption restrictions were imposed for more than 4 months.

The solution to such problems could be the introduction of distributed generation (DG) facilities of the required capacity close to important consumers, which would provide a reliable power supply for emergency armor power consumers and reduce the volume of restrictions. In addition, the introduction of DG relieves the load of power centers and reduces the duration of the technological connection procedure with an overall increase in reliability, which corresponds to the concept of digital transformation.

Various methods are used to plan the development of energy and electrical engineering complexes based on economic and mathematical models. In Russia, the Power System Development Program requires several models.

*Corresponding author: paskar-ivan@mail.ru 
The most common models for planning the development of power systems are MARKAL-TIMES [1], MESSAGE (Model for Energy Supply Strategy Alternatives and their General Environmental Impact) [2], Electricity Market Module (EMM) [3]; Integrated Planning Model (IPM) [4], PLEXOS [5], OSeMOSYS (Open-Source Energy Modeling System) [6], Backbone VTT [8], TEMOA (Tools for Energy Model Optimization and Analysis) [8], SCANER [8].

It is possible to highlight the main trends in the development of models for the power systems development.

First, this is the use of multi-parameter and multi-criteria models, which take into account technological aspects and take into account the connections between the subjects of the power system. The modeling takes into account the parameters and characteristics of all participants in the process: generating companies, energy sales organizations, grid companies, as well as consumers of electrical energy and power.

Secondly, in addition to aforementioned organizations, the local businesses are also involved in the modeling of the regional energy system development. Local actors have a significant impact on the operation of the power distribution system. This is due to the active development of microgrids and the ability to regulate consumption patterns.

Third, the creation of conditions for the modernization of regional energy systems. The search for the optimal solution is carried out using simulation and assessment of technological, economic, environmental characteristics of the generating facility planned for commissioning. Federal and regional authorities are interested in attracting private investors in the renovation and construction of new facilities in the energy sector, their tasks are to create investment attractiveness.

\section{Methodology}

To develop models for the development of power systems, a technocenosis can be applied, which can satisfy all the trends that are given above.

When analyzing the need to introduce distributed generation facilities in the region, the first step is to analyze the existing sources of electricity. Units of power plants of the Kuzbass power system were selected as individuals of the technocenosis, which will accurately describe the situation, since they work separately from each other and come out of the cenosis (due to repairs, emergencies). Figure 1 shows the algorithm by which the analysis was carried out.

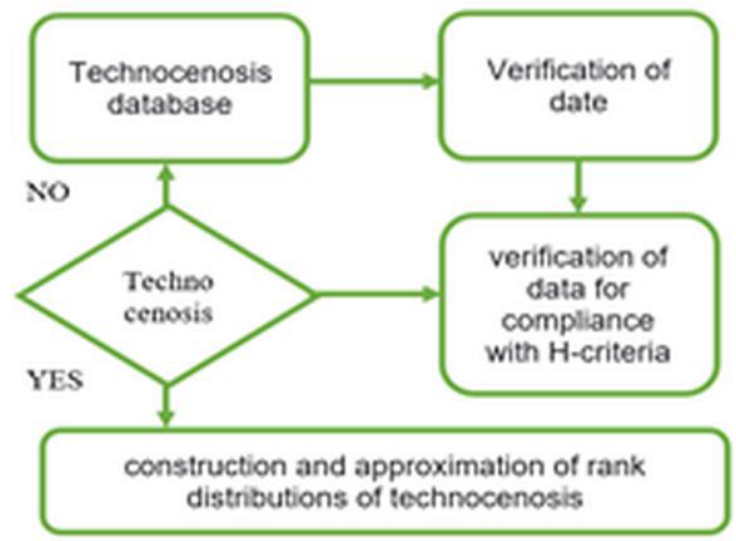

Fig. 1. Algorithm for object research 
The distinguished technocenosis corresponds to all the distinctive features: the number of cenosis elements is almost infinite, each individual is a structural unit, a single infrastructure is distinguished, constant development is characteristic, the presence of weak connections (electrical, informational, technological).

Next, the rank H-distribution is constructed, which is described by the following mathematical expression:

$$
W(r)=\frac{W_{1}}{r^{\beta}}
$$

where $\beta$ is a characteristic indicator that determines the degree of slope of the curve, $r$ is the rank of the object, $W_{l}$ is the value of the installed capacity of the largest object (generator).

The characteristic indicator according to [8] is the best in the range of states of the technocenosis described by rank-species distributions with $0,5 \leq \beta \leq 1,5$.

A statistical distribution can be called normal if the dependence of its mean and variance on the sample size is insignificant. The probability distribution, which in the one-dimensional case is given by the distribution density function, is expressed by the following equation:

$$
f(x)=\frac{1}{\sigma \sqrt{2 \pi}} e^{-\frac{\left(x_{i}-\mu_{i}\right)^{2}}{2 \sigma^{2}}}
$$

where the parameter $\mu$ is the mathematical expectation, the median and the distribution mode, and the parameter $\sigma$ is the standard deviation $\left(\sigma^{2}\right.$ - variance) of the distribution.

Then, the obtained results are analyzed by testing the hypothesis about the inconsistency of the general population with the normal distribution according to the Pearson criterion (3) and testing the hypothesis about the normal distribution by the method of rectified diagrams:

$$
\chi^{2}=\sum_{j=1}^{e} \frac{\left(n_{j}-n p_{j}\right)^{2}}{n p_{j}}
$$

If the points do not lie around any one straight line, then the interrelated data are checked using the concordance coefficient, which is determined for the set of rank distributions and shows the degree of interconnection of the technocenosis (4):

$$
W=\frac{12 S\left(\Delta^{2}\right)}{m^{2}\left(n^{3}-n\right)-m \sum_{j=1}^{m} T_{j}}
$$

where $m$ is the number of groups that are ranked, $n$ is the number of variables, $T_{j}=\sum_{t=1}^{t}\left(t_{t}^{3}-t_{t}\right)-$ an indicator of related ranks in the ranking, $S=\frac{\sum_{i=1}^{n}\left(\sum_{j=1}^{m} R_{i j}\right)^{2}-\left(\sum_{i=1}^{n} \sum_{j=1}^{m} R_{i j}\right)^{2}}{2} R_{i j}$ - the rank of the $i$-factor at the $j$-unit.

Then the sample coefficient of linear correlation is calculated, which is determined for a pair of rank distributions and characterizes the degree of interconnection (5).

$$
R=\frac{\sum_{i=1}^{n 1} S_{i}}{n 1^{2}-n 1} \cdot 100
$$


After that, an approximation is carried out. Each distribution in graphical form is a set of points obtained from empirical data (6).

$$
\left(x_{1}, y_{1}\right) ;\left(x_{2}, y_{2}\right) ; \ldots ;\left(x_{i}, y_{i}\right) ; \ldots ;\left(x_{n}, y_{n}\right)
$$

where $i$ is a formal index; $n$ is the total number of points.

The points are the result of the analysis of the tabulated rank distribution of the technocenosis. Each of the distributions has its own number. From the point of view of the subsequent optimization of the technocenosis, the approximation of empirical distributions is of great importance. Its task is to select an analytical relationship that best describes the set of points. Specified, we set as the standard form a hyperbolic analytical expression of the form (7):

$$
f(x)=\frac{A}{x^{a}}
$$

where $A$ and $x$ are parameters.

\section{Results and discussion}

Based on the results of the rank analysis of the units of power plants in Kuzbass, a parametric distribution for 2020 was constructed (Figure 2).

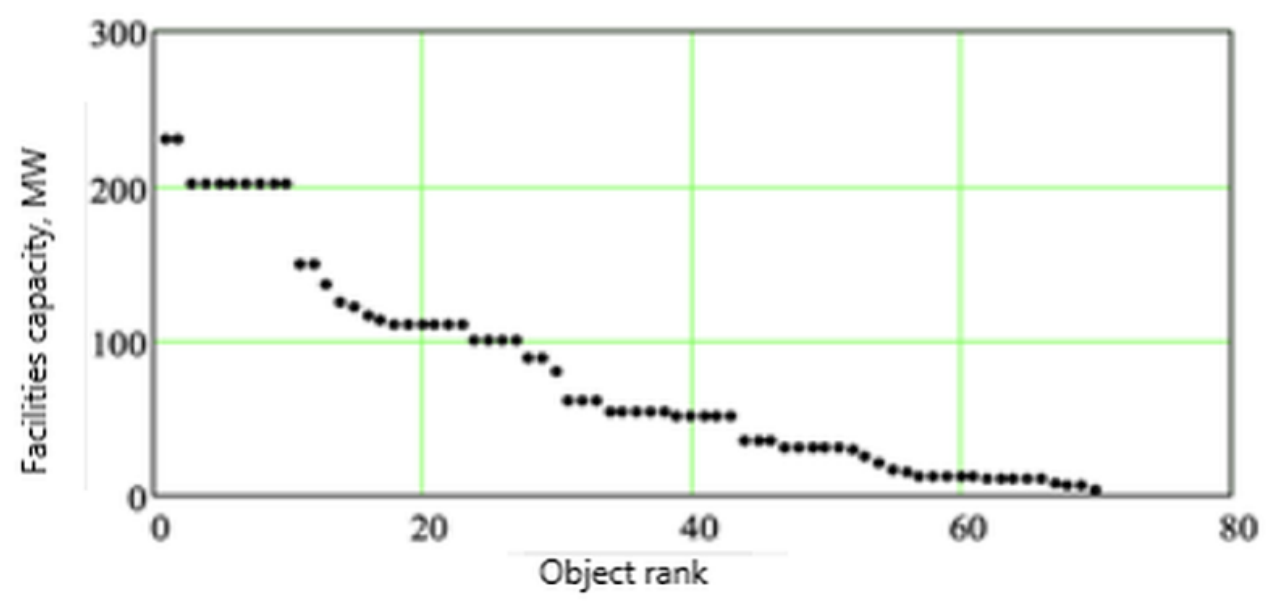

Fig. 2. Ranking parametric distribution of the technocenosis of the current state of regional power generation units

Analyzing the obtained distribution, it can be seen that there is no smooth transition of the unit capacities, after $200 \mathrm{MW}, 148.8 \mathrm{MW}$ immediately goes. This state is a consequence of the development of large power plants with the best indicators of energy efficiency with insufficient attention to the development of small generation.

Next, we check the method of rectified diagrams, we get the following graph (Figure 3), which shows that the points do not lie along any one straight line. This means that the hypothesis of a normal distribution of the general population can be rejected. 


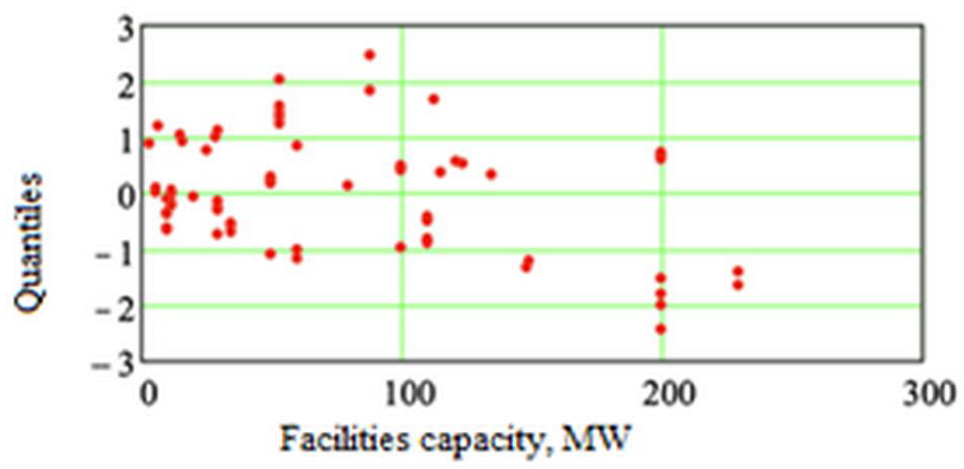

Fig. 3. The graph of the method of straightened diagrams

Considering that all points do not lie near one line, the nature of the graph confirms the hypothesis that the object of research is a technocenosis. Due to this, in the future, when working with statistical data, it is possible to apply the methodology of rank analysis.

Parameters of approximating curve allowed us to construct the graph in Figure 4.

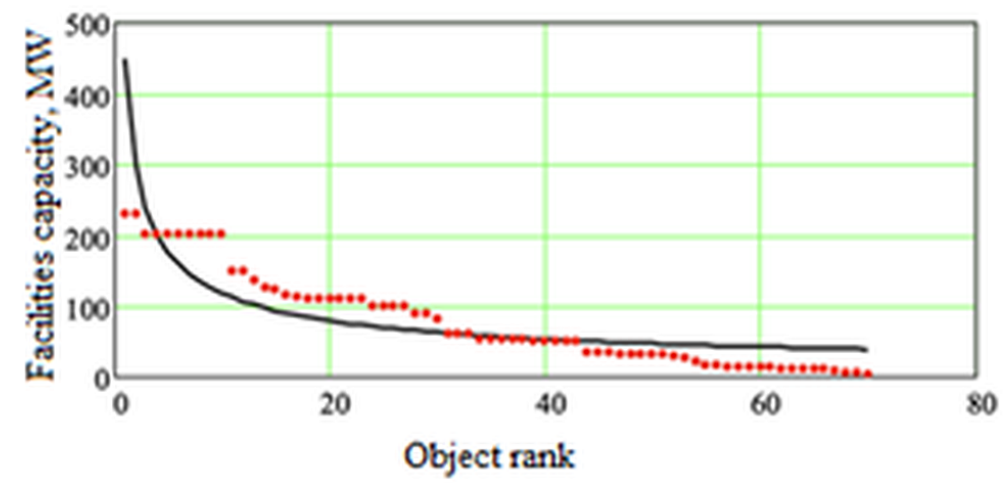

Fig. 4. Results of approximation of operating power generation units

Next, the rank distributions are approximated by the linear least squares method. Having received the values of the regression coefficients, it is possible to restore the original dependence. After the procedure of approximation by the nonlinear method, the following matrix and analytical dependence were obtained $(10,11)$ :

$$
\begin{gathered}
T\left(V^{\langle 1\rangle}, R\right)=\left(\begin{array}{c}
1,006 \\
1,339 \cdot 10^{3}
\end{array}\right) \\
W=\frac{1.339 \cdot 10^{3}}{r^{1,006}}
\end{gathered}
$$

The chart rank distribution is presented on the Figure 5. 


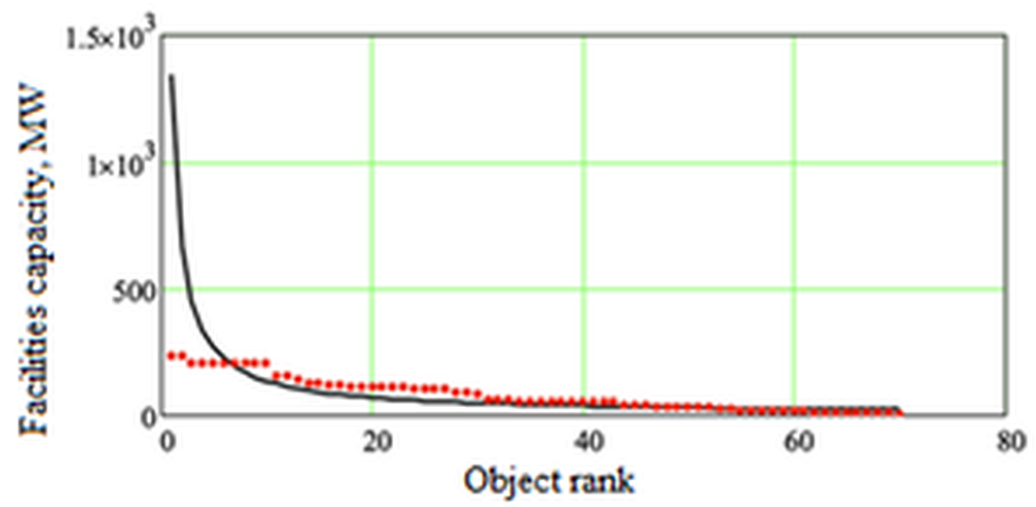

Fig. 5. Rank parametric distribution

Further, the estimation is carried out according to the true error by the methods of least squares (LSM) and least moduli (LSM). According to the results of evaluating the true error, the nonlinear least squares method is more correct in the range of stable states of the technocenosis $0,5 \leq \beta \leq 1,5$.

We carry out the same analysis according to program documents of generating complex in the region. These programs do not provide for the construction of new power plants, but only for the modernization and increase in the capacity of the existing ones.

According to the Power System Development Program of the Kemerovo Region 20212025 , an increase in power generation capacity in the territory of the Kemerovo Region Kuzbass is predicted (taking into account the commissioning and dismantling), a decrease in generating capacities at the power plants of the Kemerovo Region - Kuzbass in the period up to 2025 by $101 \mathrm{MW}$ (relative to 2020).

$$
W=\frac{411,653}{r^{0,556}}
$$

As we can see, the value has practically not changed, the generating complex will not become more stable.

In April 2020, an agreement was signed between JSC RusHydro and the Administration of Kuzbass for the development of a project for the construction of the Krapivinskaya HPP with a capacity of $300 \mathrm{MW}$ (three units with a capacity of $133 \mathrm{MW}$ each). Considering this, the situation in the technocenosis of the region will change, taking into account the planned activities (13):

$$
W=\frac{432,957}{r^{0,556}}
$$

\section{Conclusion}

To achieve high stability (survivability) of the region's power supply system, it is necessary to add a "tail" to the H-distribution. The construction and commissioning of the Krapivinskaya HPP will not allow increasing the survivability of the power system. The addition of small power plants that would be installed at the consumer and, thus, allow achieving sustainable $\mathrm{H}$-distribution, also increase the reliability and quality of power supply in the power system. The development of the system, taking into account the cenological parameters, will be able to increase the reliability of operation, the quality of electricity (due to the construction of small power plants), and the energy security of the region. 
In the future, it is necessary to determine the locations (places) where the construction of small power plants is advisable not only from the point of view of the operating modes of the power system, but also justified from the point of view of the socio-economic development of the subjects of the regional power system.

\section{References}

1. MARKAL-TIMES: http://www.iea-etsap.org/web/Markal.asp

2. Modelling Nuclear Energy Systems with MESSAGE: A User's Guide, Nuclear Energy Series No. NG-T-5.2, IAEA, 2016. http://wwwpub.iaea.org/MTCD/Publications/PDF/Pub1718 web.pdf

3. The national energy modeling system: an overview 2009, U.S. Energy Information Administration, DOE/EIA-0581, 2009, http://www.eia.gov/oiaf/aeo/overview

4. EPA Base Case v.5.15 Using IPM. U.S. Environmental Protection Agency. 2015. https://www.epa.gov/sites/production/files/201508/documents/epa_base case_v.5.15 incremental_documentation_august_2015.pdf

5. PLEXOS Integrated Energy Model. Energy Exemplar, 2020. http://energyexemplar.com/software/plexos-desktop-edition/

6. M. Howells, H. Rogner, N. Strachan, C. Heaps, H. Huntington, S. Kypreos, A. Hughes, S. Silveira, J. Decarolis, M. Bazillian et al., Energy Policy, 39, 5850 (2011)

7. N. Helistö, J. Kiviluoma, J. Ikäheimo, T. Rasku, E. Rinne, C. O’Dwyer, R. Li., D. Flynn, Energies, 12, 3388 (2019)

8. K. Hunter, S. Sreepathi, J.F. DeCarolis, Energy Economics, 40, 339 